\title{
e-Tracking COVID-19 Disruptions to the Global Development Agenda on Land
}

\author{
Uchendu Eugene Chigbu* \\ Department of Land and Property Sciences, Namibia University of Science and Technology, Namibia
}

Submission: September 02, 2020; Published: September 18, 2020

*Corresponding author: Uchendu Eugene Chigbu, Department of Land and Property Sciences, Namibia University of Science and Technology, No. 13 Jackson Kaujeua Street, Private Bag 13388, Windhoek, Namibia

Abstract

Investigations into the outbreak of COVID-19 or Coronavirus has rapidly evolved in the aspects of information update on deaths and casualties, and the search for medically certified preventive and curative measures. One aspect that remains poorly explored is its disruption to global land (and natural resources) discourse for achieving global sustainable development. This study addresses this gap by conducting a retrospective e-content analysis of social media vignettes posted on Twitter between 1st February and 31st May 2020, to analyse its disruptions to the global land and related issues. It makes four crucial revelations. (1) The COVID-19, like earthquakes and volcanoes, is a viral disaster which has caused disruptions to the global discourse on land. (2) It has led to new land information that provides evidence that health issues have a qualitative relationship to land issues. (3) It has also led to positive societal attitude to hygiene, which has implications on health, sanitation and environment. (4) It has created new funding opportunities for improving health, sanitation and environment. By providing details on these findings, the study contributes to the literature that reminds all stakeholders that the COVID-19 outbreak must be curtailed without a loss of attention to other critical global issues, such as land-related concerns.

Keywords: Coronavirus; COVID-19; e-content analysis; Land; Land governance; Sustainability; SDGs

Abbreviations: SDGs: Sustainable Development Goals; BBC: British Broadcasting Service; CAMS: Copernicus Atmosphere Monitoring Service

\section{Introduction}

The global discourse on land and related issues (including environment and climate change) has far-reaching implications on how the development agenda will be achieved [1,2]. Landrelated concerns are directly linked to alleviation of poverty, hunger, climate change and global warming [1-4]. This is because how people use land determine the direction of human and physical developments. Hence, the land discourse is a prerequisite to achieving specific Sustainable Development Goals or SDGs $[5,6]$. Land will play a crucial role in the achievement of at least five (of the seventeen) SDGs. These are SDGs 1, 2, 5, 11 and 15. These five SDGs have a focus on poverty, hunger, gender equality, sustainable cities, and peace respectively. Together, achieving any or all these SDGs demands for improvements food security, nutrition (including agriculture production), access to land and inputs, reducing income inequality between men and women, improving land use planning and administration systems in rural and urban areas; reducing and resolving land and natural resource conflicts; and reducing risk of land degradation and deforestation $[6,7]$. With these goals fully developed (with their targets for their achievement already set) and actions for their achievement under implementation, the global land sector community depend on discourses to inform and share experiences for better results. Situations such as natural disasters and disease outbreaks have the potential to disrupt (positively or negatively) the path to success. Disease outbreaks have been identified to have similar impact on land-based activities, including on community interaction and socioeconomic productivity from land [8]. The challenge is that there is still paucity of research dedicated to disease outbreak and land management. Hence, the unavailability of reputable literature on the subject $[8,9]$.

Disease outbreaks play a crucial role in shaping human societal development. It has strong linkages to social cohesion, economic productivity, political gameplay, and population growth (to mention a few) [8-10]. However, the profile of critical outbreaks in the history of humankind is a scary one. The earliest recorded incident is the Bubonic Plague of the Justinian period. The plague which originated from Europe killed nearly a half of the population of Europe between the years 541 to 542 [11]. Then came the Black Death, another form of the Bubonic plague which originated from Asia. It killed between 75-200 million people from 1346 to 1353 $[11,12]$. Cholera has hit the world more than six times. The third cholera pandemic (which originated in India), ended the lives of 
over a million people in the 19th century lasting from 1852 to 1860 [12,13]. The Asian Flu (1956-1958), a pandemic outbreak of Influenza A of the H2N2 subtype which originated in China in 1956 and lasted until 1958, killed about two million people [14]. The death toll from HIV/AIDS pandemic, first identified in the Democratic Republic of the Congo in 1976, has reached more than 36 million [15]. Some of these outbreaks make the Ebola and HIV outbreaks seem medically tolerable, in terms of their death tolls. They altered human behaviours and the visions for development in the human settlements they ravaged. However, the impact of these outbreaks on global development agendas have not been fully studied, mostly due to a lack of interest by scholars or a poor understanding of the need to do so [8,11-14].

Disease outbreaks have a unique way of redefining regional and global health geographies. This is noteworthy because health geography, anywhere, overlaps with public health in subjective ways [8]. This has multiplier implications on pertinent issues that impact on human development at all levels - whether local, national, continental or global [8]. Evidences from previously document disease outbreaks [11-16] have shown that people or societies do not have to be sick to be affected by ill health or discomforts caused by disease outbreaks. This is exemplified by the ongoing experience. The outbreak of coronavirus disease (COVID-19) has placed unprecedented challenges on all aspects of human life. The situation is rapidly evolving in the aspects of information update on death tolls; and the search for medically certified preventive and curative measures. However, the quantitative and qualitative costs of the COVID-19 outbreak to various aspects of human living remains largely unaccounted.

It is crucial to investigate how much (qualitatively) it is affecting activities that are linked to land to ensure that it does not derail the effort towards achieving the global agenda on land. This study uses the available evidence from social media to show the qualitative impact of the outbreak to the global land discourse and discusses check them. In addition to the introduction (first section), the study is broadly organized into five sections. The second (or next) section provides detail on how the study was conducted. The third section presents the outcome of the study. It is focused on identifying the disruptions caused by the outbreak on matters related to the global land sector. This is followed by the fourth section, which reflects on ways of ensuring that the identified disruptions are curtailed to ensure that they do not negatively impact on the achievement of the global development agenda on land related issues. Finally, the fifth section provides a conclusion on the way forward.

\section{Methodology}

\section{Design}

The study is based on a retrospective e-content analysis of social media vignettes (related to the outbreak of COVID-19 or Coronavirus) posted on social media between $1^{\text {st }}$ February and $31^{\text {st }}$ May 2020, to analyse its disruptions to the global land and related issues. It puts focus on deciphering reported disruptions (caused by the outbreak of COVID-19 or Coronavirus) to the discourses in the global land sector due to postponements and cancellation of land discourse events. In this study, social media vignettes were considered to be only Twitter posts. The analysed vignettes include contents depicted in texts and visuals (including audio and video) posted on Twitter (concerning the outbreak of COVID-19 or Coronavirus in relation to land related events) during this period; and which was accessible to the researcher. The reason for focusing on the Twitter platform is because it is one of the most accessible social media platforms used by individuals, governments and organizations to make short announcements or report on ongoing affairs globally. Data collection from Twitter, and the use of (or reliance on) Twitter data is what makes this study unique. A review of Twitter based online depictions of the impact of the COVID-19 or Coronavirus outbreak on planned events that are meant to contribute to achieving the global development agenda is imperative. Twitter offers a quick way to gain direct content data that can be easily reviewed following conventional or improvised content analytical methods.

\section{"Twitter" review}

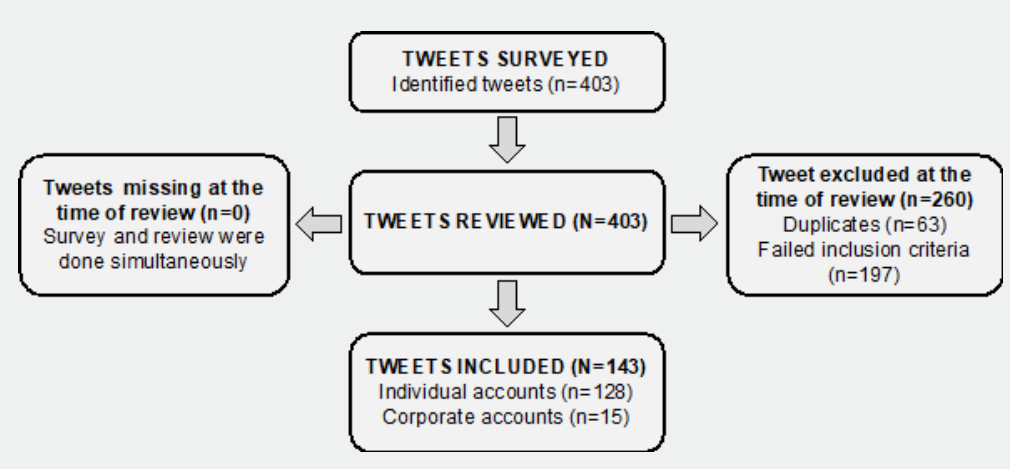

Figure 1: Flowchart of steps followed to identify Tweets about land issues in related to the COVID-19. 
Searches were conducted on Twitter using a combination of the following keywords: \#COVID-19 \#land, \#Coronavirus \#Land, \#sanitation \#coronavirus, \#land \#events \#COVID-19, \#COVID19 \#development \#Plan, \#COVID19 \#fund, \#Wuhan \#virus \#effects, \#conoravirus \#land \#information \#data. The Twitter search was designed to meet the following inclusion criteria: (a) posted within the timeframe between 1st February and 31st May 2020. (b) related to COVID-19 or Coronavirus with links to land-based activities or news; (c) not a promotional post or an advertisement. Following the identification of 403 tweets from the initial search, the researcher reviewed them to confirm that they met the inclusion criteria (Figure 1).

Of these, 63 were duplicate results, 197 tweets did not meet the inclusion criteria and no tweets were found missing (either deleted by account owners or removed by Twitter) by the time of the review. No tweets were found to be missing during review because the researcher conducted the searches and review simultaneously during each search per keywords (hashtags) used. This was possible as most tweets were limited to either 140 characters or 1-2 photos, audio files or videos. A total of 143 tweets were included in the final sample, of which 15 correspond to corporate tweets and 128 to individual. For details on the collection of internet-based data for analysing land issues, refer some scholars [17-20] who have applied the same approach using Twitter, LinkedIn and ResearchGate.

\section{E-content (data) analysis}

The resulting data from the survey was conducted following (with slight deviations) Ferré-Eguiluz et al. [21] approach to content analysis [21]. The approach is best described as e-content analysis due to the nature of the data collected and used. FerréEguiluz et al. [21] considered broad "media coverage" in their research, but this study considered only internet-based social media coverage. Also, Ferré-Eguiluz et al. [21] media document used "any newspaper coverage (including journal or magazine articles, reports, and editorials) and radio coverage (including audio of radio news, programs, and interviews). This study deviates hugely by focusing on Twitter (as sole social media platform). Despite following Ferré-Eguiluz et al. [21] two-steps media content analysis, this study chose to (re)define its approach as e-content analysis rather than a conventional (or extensive) content analysis because it analysed Twitter posts (tweets or vignettes) rather than articles. The e-content analysis was conducted in the following two steps:

Step 1 involved fact-checking and verification of e-contents (tweets): The researcher is aware that social media (including Twitter) contain a lot of unconfirmed and unverified e-contents (including news, propaganda, and viewpoint). Hence, a possible limitation to this study is that some tweets (and information content of some of the tweets) may portray inaccurate information as at the time they were tweeted or during the period of data collection. However, all possible effort was put to ensure accuracy. This was done by verifying some of the tweets with contents in regular or mainstream media. A starting point for the analysis was to fact-check the tweets. Efforts were made to verify the authenticity of the tweets analysed. This was done by locating the original information on the web or corroborating them with literature (including grey documents, academic publications and other online sources). Tweets that originated from corporate entities (such as television, radio and newspaper organisations) were considered authentic as at the time they were tweeted. These verification efforts were put in place to limit inaccuracies.

Step 2 involved the classification of tweets into themes: The tweets were classified into themes based on the three major issues that can pose danger to the achievement of the global agenda on sustainable development (within the context of land). These include the limitation to funding, paucity of data for decision-making, and limited opportunities for knowledgesharing between partners (including individuals, nations, and organizations) implementing the agenda [22-25]. These three factors have been considered crucial in this study because they would have the greatest impact on the failure to achieve the land-based aspect of the SDGs (i.e. SDGs 1, 2, 5, 11 and 15.). The researcher coded the tweets that emanated from the survey by labelling each of them against one of the three factors of identified to have possible effect on the land-based aspect of the SDGs. Each tweet was labelled following their closest leaning to any of the following coding structure based on the following representations: $F_{u}$ for tweets that indicate impact of the outbreak on funding, $D_{a}$ for tweets that indicate effect of the outbreak on data, and data for decision-making, and $K_{n}$ for tweets that reflect a link of the outbreak on knowledge-sharing between partners. In addition to the three factors identified in literature, the study provided room for other $\left(O_{t}\right)$ factors which may be possibly emerge from the outbreak of the COVID-19. These codes were assigned (-) or ( + ) signs depending on whether they represent negative or positive scenarios. They are expressed as follows:

$$
\text { Codes }=+F_{u^{\prime}}-F_{u^{\prime}}+D_{a^{\prime}}-D_{a^{\prime}}+K_{n^{\prime}}-K_{n^{\prime}}+O_{\iota^{\prime}}-O_{\iota^{\prime}}
$$

Where

$+F_{u}$ or $-F_{u}$ codes represent positive or negative influences on funding.

$+D_{a}$ or $-D_{a}$ codes represent positive or negative influences on data availability.

$+K_{n}$ or $-K_{n}$ codes represent positive or negative influences on face-to-face knowledge-sharing.

$+O_{t^{\prime}}$ or $-O_{t}$ codes represent positive or negative influences not found in $+F_{u^{\prime}}-F_{u^{\prime}}+D_{a^{\prime}}-D_{a^{\prime}}+K_{n^{\prime}}-K_{n^{*}}$

The above coding structure was done manually but using electronic code sheets designed in Microsoft Excel [26]. Following this coding structure, it was possible to descriptively calculate the scale (and frequency) of how each theme relate to the outbreak's 
influence on issues related to land. It was also possible to use the various themes to develop a meaningful narrative on the issue of COVID-19 or Coronavirus and global land issues, as represented on Twitter.

\section{Critical Issues Emerging from Social Media Contents}

\section{The scenarios (and occurrence) of COVID-19}

In broad terms, the emerging data from the tweets show that the number of tweets that report disruptions caused by COVID-19 or Coronavirus have positive and negative aspects. However, it is predominantly negative, with only little positive aspects. The themes that emerged most frequently, based on the coding structure adopted, were related to $-K_{n}(\mathrm{n}=103,72 \%),+K_{n}(\mathrm{n}=16$, $11.1 \%),+F_{u}(\mathrm{n}=0,0.0 \%),+F_{u}(\mathrm{n}=0,0.0 \%),-D_{a}(\mathrm{n}=0,0.0 \%),+D_{a}$ $(\mathrm{n}=2,1.4 \%),-O_{t}(\mathrm{n}=13,9.1 \%)$, and $+O_{t}(\mathrm{n}=9,6.4 \%)$ (see Figure 2).

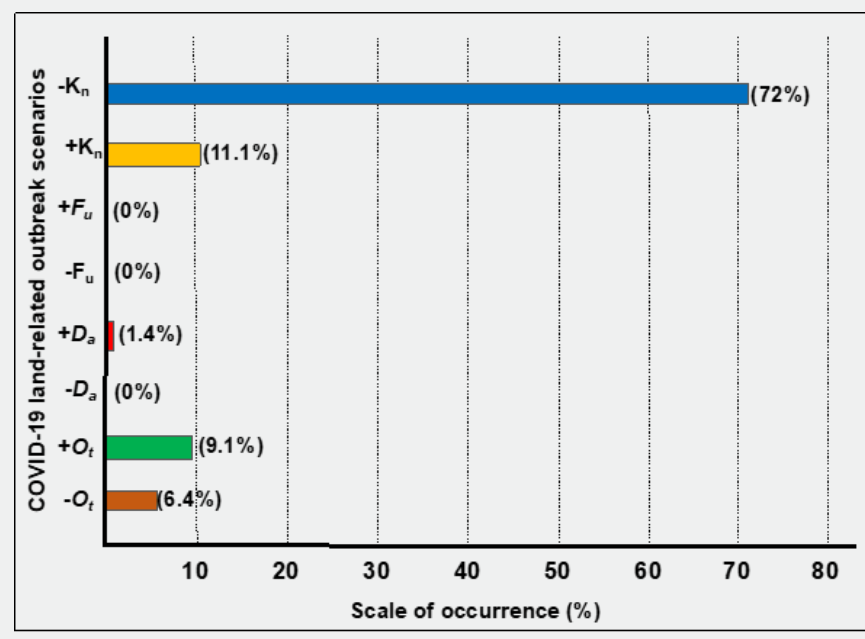

Figure 2: Occurrence of tweets reflecting influence of COVID-19 outbreak on land-related issues.

The very high frequency of $-K_{n}$ (in relation to $+K_{n}$ ) is indicative of a gross impact of the outbreak on direct knowledge sharing on issues related to land as part of the global development agenda. This high scale of negativity observed on $-K_{n}$ (in relation to $+K_{n}$ ) is also indicative of an urgent need for providing alternative means of knowledge-sharing for a that are non-physical or finding a quicker way to tackling the outbreak to ensure safety in physical for a for land discourse.

The higher null (zero) frequencies observed in $-F_{u^{\prime}}+F_{u}$ and $-D_{a}$ are indicative of a lack of interest by Twitter users on issues related to funding. However, there are other pertinent issues (other than issues concerned with $+F_{u^{\prime}}-F_{u^{\prime}}+D_{\alpha^{\prime}}-D_{a^{\prime}}+K_{n^{\prime}}-K_{n}$ ) which reflected in the $+O_{t}$ and $-O_{t}$ scenarios. The inference from these tweet-data is that the COVID-19 outbreak has caused more negative disruptions in face-to-face land discourse and knowledge-sharing than in other aspects. However, they neither identify the actual landrelated issues affected by the outbreak nor how it was affected by the outbreak.

\section{Actual Land-related issues affected by the COVID-19 outbreak}

Having analysed the frequency of tweets that reported various aspects of disruptions, it was possible to identify from those tweets the actual incidences (including land forums and related events) reportedly disrupted, as well and calculate the sum of the identified disruptions. Disruption (as has been used in this study) implies cancellation and postponements of land events or changes to usual state of affairs that relate to land. It is also important to note that cancellation and postponements of land events excludes a change of conference platforms (e.g. change from face-to-face to online chat and discussion forums or webinars).

Based on the tweets analysed, a total of cases $(n=452)$ of land related issues (including negative disruptions, positive behavioural changes and other issues emerging) were caused (or emerged) from the COVID-19 outbreak. These have been presented according to their frequency of occurrence (Figure 3).

Four categories of land related issues were identified. Land discourse forums (e.g. conferences, workshops, seminars and related events); land information (e.g. air quality data and carbon footprints); funding opportunities (e.g. water, sanitation and hygiene) through better environmental planning; and other situations (e.g. less air pollution, less carbon footprints, better behavioural hygiene in affected cities). Scale of occurrence reflect as follows: land discourse forums disrupted ( $\mathrm{n}=302,66.8 \%$ ); land information created $(n=28,6.2 \%)$; funding opportunities created ( $\mathrm{n}=108,23.9 \%$ ); and other land related situations created $(\mathrm{n}=$ $14,3.1 \%$ ). From these data, it is possible to infer that (from tweet evidence), no land related conference was convened as a result of the outbreak, but multiple events were disrupted. The outbreak 
has no influence on existing land information (or data) but it created opportunities for new data. It has no influence on existing funding, but rather created opportunities for new funding. The outbreak also has influence on the behavioural aspects of people living in COVID-19 affected cities, which resulted to land-related effects such as less air pollution, less carbon footprints and better behavioural hygiene in affected areas.

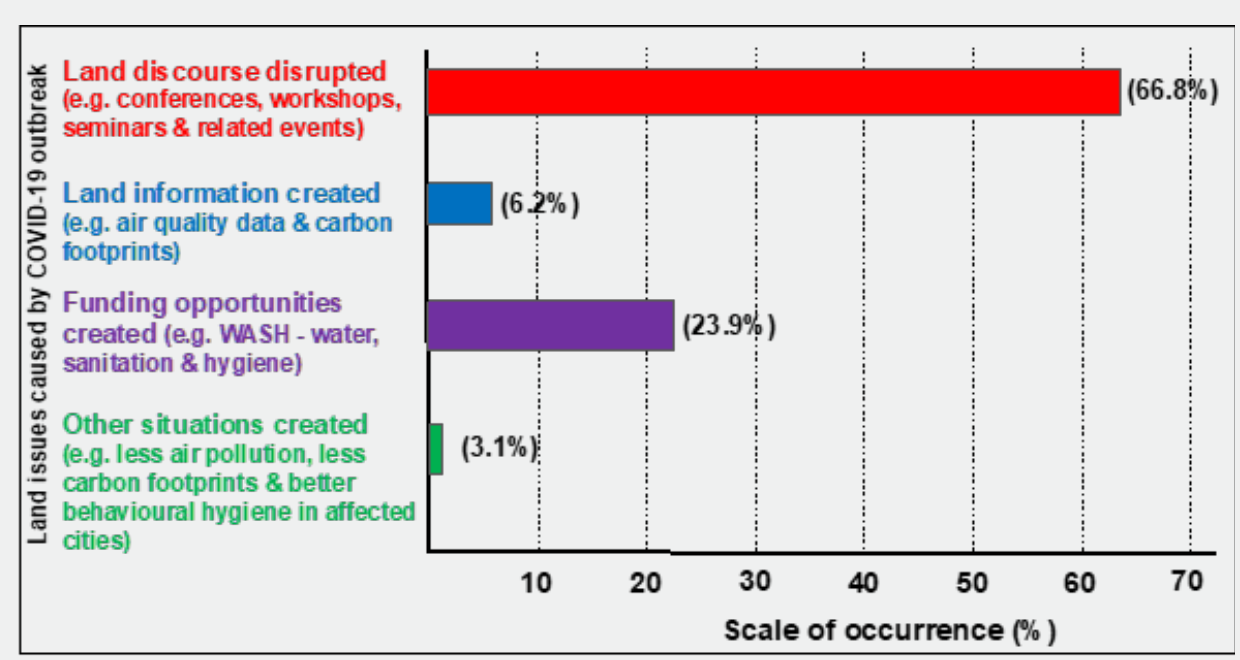

Figure 3: Direct representation of events disrupted by the COVID-19 outbreak.

In order to grasp the qualitative impact of the outbreak, details on the nature of the reported disruptions caused by the COVID-19 outbreak is necessary. It would allow for evidence of the critical specific land issues reported in the tweets. It will also pave a ground for a more informed discussion on the consequences of the outbreak (and its apparent global efforts) on the global land discourse and agenda.

Table 1 provides a Summary of contents (key issues that affect land) as reported in the tweets. The issues identified represent the critical matters that reflect the land-health nexus [16,27] as reflected tweets on the COVID-19 outbreak.

Table 1: The scenarios and incidence disrupted as a consequence of the COVID-19.

\begin{tabular}{|c|c|}
\hline Major land issues disrupted by COVID-19 outbreak ${ }^{1}$ & Summary of contents as reported by tweeps ${ }^{2}$ \\
\hline $\begin{array}{l}\text { Land discourse disrupted (e.g. conferences, work- } \\
\text { shops, seminars and related events) }\end{array}$ & $\begin{array}{l}\text { Postponement (and later cancellation) of the Annual World Bank Conference on land and } \\
\text { poverty }{ }^{3} \text { [28]. Natural Products Expo } 2020^{4} \text { [29]. }\end{array}$ \\
\hline $\begin{array}{l}\text { Funding opportunities created (e.g. water, sanitation } \\
\text { and environmental planning) }\end{array}$ & $\begin{array}{l}\text { As the epidemic got worse, more governments have committed more financial resources to } \\
\text { ensuring WASH (water, sanitation and hygiene) in the environment [30]. }\end{array}$ \\
\hline $\begin{array}{l}\text { Behavioural situations created (e.g. less air pollution, } \\
\text { less carbon footprints and better behavioural hygiene } \\
\text { in affected cities) }\end{array}$ & $\begin{array}{l}\text { Globally, behavioural hygiene is reported to have improved due to people taking precaution- } \\
\text { ary measures to avoid contact with those affected by the virus; especially in meat and fish } \\
\text { production and markets [31,32]. } \\
\text { Improvement in air quality in COVID-19 affected cities in China due to reduction in industri- } \\
\text { al activity }[33,34] .\end{array}$ \\
\hline $\begin{array}{l}\text { Land information created (e.g. air quality data and } \\
\text { carbon footprints) }\end{array}$ & $\begin{array}{l}\text { Due to reduced industrial activity in China. New data (observed from satellite image) shows } \\
\text { a } 30 \% \text { decrease in air pollution over China as the outbreak forced factories to close, airports } \\
\text { to cancel flights, and affected (suspected) citizens to go into quarantine [33-35]. }\end{array}$ \\
\hline
\end{tabular}

'These issues were verifiable because the reporting tweets were accompanied by internet links to primary sources.

${ }^{2}$ This is a term or word used to describe Twitter users.

${ }^{3}$ This is the largest global forum for discourse and data sharing on land policy, geoinformation and land management. The conference has been held nonstop for the past 20 years, until cancellation of the 21 st event. It is usually accompanied by hundreds of pre- and postconference workshops on various aspects of land.

${ }^{4}$ World's largest and premier tradeshows for natural, organic and healthy products industry. 


\section{Discussion: What the Tweets Report and Communicate} about COVID-19 and Land Issues

It is widely acknowledged that land and natural resource are at the centre of the global development agenda $[1,2,36]$. This is because harnessing land (and its associated natural resources) are mandatory for reducing poverty because they ensure social inclusion and economic development $[7,9,37]$. Increasingly, land is a key concept, factor and object in the global effort to achieve change and sustainability. In the face of many land related challenges-growing urbanisation, rural development, climate change, environmental risk issues and a host of socioeconomic problems-the incursion of the COVID-19 into has become an ever-increasing concern. "This is specifically disturbing in areas characterised by slum settlements, poor sanitation and poor health facilities" [8]. Evidence from the e-content analysis of tweets reflect that the outbreak is of global concern to land related matters.

These are evident in the following tweet. A tweep, @finn_ harvor, noted that: "The immense impact that the coronavirus is having on Korea and China is also causing environmental changes - some positive, some negative. These effects will need debate once crisis over." Another tweep, @EcoInternetDrGB who reflected it in a comparative manner, noted that "Fighting climate change should not come at expense of fighting viruses". Thereby indicating a competitive edge between the fight against coronavirus and that of a land related issue like climate change. These tweets are indications that the outbreak of the COVID-19 has consequences that are related to land. These are discussed under the following themes below (which derived from the previously mentioned outcomes of this study).

Disruptions to land discourse implies disruption in global networks and collaborations towards achieving the global development agenda on land

Land professionals do not want to be exposed to large groups of people with the risk of transmitting the COVID-19 or coronavirus. As a result, many land (and related natural source) conferences and events have either been indefinitely postponed or cancelled. These cancellations have direct impact on participation in the global land discourse.

Participation is an essential part of the efforts to actively engage stakeholders and empowerment vulnerable groups with capacity development through learning about land rights. It motivates inclusion (in both theory and practice) in the global land governance and land management processes $[1,2,6,7,8,17,37]$.

Conferences (including workshops, seminars and symposia) on land are the most reliable platforms for large groups of people who share the global development vision (e.g. the effort to achieving the SDGs) have to share knowledge on the "how-to" aspect of initiatives on land. It also presents opportunities for partnerships and networking, which is a crucial part of promoting collaborations in the delivery of land administration and land governance services across the world in the global land sector. These events are places to learn new land methods, encounter innovative ideas and discover new land-related products and services (e.g. geospatial technologies and policy-driven case studies) that are emerging globally.

Considering the importance of maintaining existing momentum in the global development discourse on land. alternative options for face-to-face conferences must be adopted. For instance, GitHub (the world's largest community of developers, who are also involved in the development of geospatial apps for land management) rather than cancel, opted to change their faceto-face conference into an online conference. As reflected in this tweet (from @Synced_Global), “GitHub is switching its GitHub Satellite conference this year from a physical, in-person event to a virtual event on May 6, 2020." This represent an option for continuing to engage stakeholder in the land discourse to ensure continuity in knowledge building to improving global solutions to land, water, environment and air quality challenges.

\section{COVID-19 outbreak has led to new land information which provides evidence that health issues have qualitative relationship to land issues}

Data (or information) on land and land-related components of development is crucial to ensure transparency, understand the dynamics of land governance perspectives, and serve as a critical consideration in all forms of policymaking (including environmental, social and natural resource decisions) processes [37,38]. The COVID-19 outbreak not enabled the emergence of new data, it also provided data that helped to understand the relationship public health issues can have with land issues processes $[8,16]$. It has also led for the call of a reevaluation of activities influencing clinical data on hospital environmental Hygiene [39]. This is probably why one of the tweeps, @JoelMCurzon, tweeted that "Pandemics are great for the environment." Then went ahead to provide BBC news link [40]. which showed with satellite data, "Satellite images have shown a dramatic decline in pollution levels over China, which is "at least partly" due to an economic slowdown prompted by the coronavirus, US space agency Nasa says". Further evidence also shows that during this period, there was $30 \%$ decrease in air pollution over China. This reduction was particularly caused by factories closures and flight cancellations due to the outbreak [33,34]. The report notes that "The Copernicus Atmosphere Monitoring Service (CAMS) observed a decrease of fine particulate matter $\left(\mathrm{PM}_{2.5}\right)$ for February relative to the previous three years of between 20 and 30 per cent, Copernicus said in a statement" [34]. According to the World Health Organisation [41]. $\mathrm{PM}_{2.5}$ is an important air pollutant that can have high negative health impacts on people. It is an atmospheric particulate matter (PM) that has a diameter of less than 2.5 micrometres (which is comparable to $3 \%$ the diameter of a human hair) [42]. 
This land related information allows for renewed data infrastructure which can be used to understand different perspectives for making decisions on the global climate crisis, particularly in China. It provides a new understanding concerning what can be done to abstain from largescale air pollution. It also provides evidence that open data can be directed towards meeting the needs of societies (a key issue which land right activists have been campaigning, for in the past decade).

\section{Some positive behavioural situations created by COVID-19}

It is evident that the fear of contracting COVID-19 has led to radical changes in the behavioural aspects of people globally, but particularly in the hard-hit areas such as China, Japan, South Korea and Europe. This is mainly because the outbreak has created a radical awareness for limited physical interactions between people in many cities (especially in China). It is well known that interaction creates linkages across age, class, race, and ethnic lines, and different groups within a place and local population [43]. When such interaction is reduced or broken through the outbreak of an epidemic, it can bring about a renewed awareness of common needs among people. In this case, to stay free from COVID-19. This disconnection can also bring about new habits, engagement in new norms or a re-embrace of old norms. In the context of COVID-19, these are easily decipherable from the following tweets. A tweep, @sarahmantione, reflected on this in this question by asking "Does anyone else feel when they are washing their hands in a public bathroom now that the people washing next to you are lowkey judging your wash, and you have to prove to them you are in fact a sanitary person?" Another tweep, @drpatfarrell, put it differently: "Do you pump your own gas into your car? Do you use a disposable glove or wipe the pump handle with a sanitizing wipe? Some things we never thought of are now essential. Hand rails, too." Focusing on China, the following tweep, @jamesvgingerich, tweeted that "The \#Coronavirus has cut China's carbon dioxide emissions by about 100 million metric tons. That's as much as Chile emits in a year". These all reflect the changing behavioural hygiene attitude that has been imposed by the COVID-19 outbreak or has been embraced by people as a result of the COVID-19 outbreak.

What have all of these to do with land? It is the change in behaviour that has led to the these rather positive behavioural situations which has led to less air pollution, less carbon footprints, and better behavioural hygiene in affected cities around the world. Hence, it is a behaviour that has responsible environmental and consumption implications. This study, therefore, suggest that epidemic outbreaks should be strongly integrated into the urban planning and development policy of every country, especially countries in the Global South.

\section{Funding opportunities created (e.g. water, sanitation and environmental)}

The greatest funding effect caused by the outbreak is in the aspect of global cashflow. In general, funding issues have a two- way effect (and upside and downside). And this is actually the reality when focusing on the global stock and commodity markets. For instance: on the downside, the oil prices plunged due to fears of the COVID-19 on the part of investors. On the upside, this same panic has led investors to scurrying towards the purchase of gold above a last seen in 2012 [....]. However, tweets investigated within the timeframe of December to March reflected only indicators of positive funding creation for water, sanitation and environmental issues. In different countries and regions, these funds are meant to contain the outbreak rather than fully dedicated to land issues.

However, because land issues (especially through its environmental and land aspects) are intricately linked to health, it was possible to identify two specific areas where the funding for COVID-19 containment has benefited local land agendas. Firstly, the World Health Organisations' Coronavirus fund is earmarked to help countries contain the outbreak by allocating part of the fund to engage their relevant ministries. These ministries include those of health, education, travel and tourism, public works, environment, social protection, and agriculture. This would mean that land focused ministries (such as travel and tourism, public works, environment, and agriculture) will have more fund to enable them to provide coordinated management of COVID-19 preparedness and response [44]. The World Health Organisation has already called for US\$675 million to fund the fight against the coronavirus and have already released more than US $\$ 15$ million to countries already hit by the outbreak [44]. Secondly, governments of the affected countries are releasing relief funding packages to contain the various. Substantial amount of these funds is channelled towards water, sanitation and the environment, which constitute critical aspects of land governance issues in those countries. Governments that have done this include China, Italy, Republic of Korea, Iran, United Kingdom, Germany, United States, among many others.

\section{Conclusion}

It is not uncommon that a global health emergency usually occur without warning, as is the case with the coronavirus outbreak. Since there is no known effective vaccines or drugs against the COVID-19, social distancing strategies such as individual and community containment, quarantine and isolation remain the most effective means of limiting transmissions [45]. Observing these social distancing strategies always comes with some repercussions that cuts across all sectors of human existence, including the socioeconomic, cultural, and environmental (including land, water and environment) aspects. A major indication that it may be affecting the land agenda reflects well in a tweet by @kevinmarsh8, which notes: “Covid19 is a major threat to health systems and economies and (with some notable exceptions) civil society and governments are taking it seriously BUT the consequences of CLIMATE CHANGE make those of Covid19 pale into insignificance-we need a similar sense of urgency." In a similar tone, the United Nations' Secretary General has warned that "Climate change is the defining challenge of our time" and 
that the world must continue to tackle it with urgency to avoid the worst impacts of global warming [46]. These are indications a section of the global community thinks that the outbreak is distracting from pursuance of the global development agenda on land (and related subjects).

The COVID-19 or Coronavirus pandemic situation has progressed in many ways. Conducted based on January-May 2020 data, it provides the qualitative disruptions of the pandemic before the first-half of 2020 .

This study contributes to literature that reminds all stakeholders that the COVID-19 outbreak must be curtailed without a loss of attention to other critical global issues, such as land related concerns. What this study has done is to situate the COVID-19 outbreak within the nexus of global land discourse to provide insights on the possible ways it has affected global activities related to land. The study used the authentic reports from tweeps on Twitter to highlights the concerns of the global online citizens on aspects of the outbreak on land governance issues. The study shows that the coronavirus outbreak is "serving as a dramatic reminder that public health is a product of our own behaviour" [47]. However, the emerging results reveal four crucial things: (1) the outbreak has caused disruptions to the global land discourse; (2) it has led to the revelation of new land information that provide evidence that health issues have qualitative relationship to land issues; (3); it has also led to some positive behavioural situations related to societal attitude to hygiene, which has implications on health, sanitation and environment; and (4) it has created new funding opportunities for improving health, sanitation and environment. It has also created economic losses for many in the corporate banking and economic production sector. This, expectedly, could mean a reduction in their funding commitments to land and environmental research (and related issues) in the coming months. The outbreak has its positive and negative implications and understanding this could pave the way for (re)planning the best ways possible towards fulfilling the landrelated aspect of the global development agenda. This is what makes this study relevant.

\section{References}

1. Gwalebe JM, Chigbu UE (2020) Participation in property formation: Insights from land-use planning in an informal urban settlement in Tanzania. Land Use Policy 92: 104482.

2. Chigbu UE, Ntihinyurwa PD, de Vries WT, Ngenzi EI (2019) Why Tenure Responsive Land-Use Planning Matters: Insights for Land Use Consolidation for Food Security in Rwanda. International Journal of Environmental Research and Public Health 16(8): 1354.

3. Mahmood HZ, Ali A, Rahut DB, Pervaiz B, Siddiqui F (2020) Linking Land Distribution with Food Security: Empirical Evidence from Pakistan. Journal of Animal and Plant Sciences 30: 175-184.

4. Carte L, Schmook B, Radel C, Johnson R (2019) The slow displacement of smallholder farming families: land, hunger, and labor migration in Nicaragua and Guatemala. Land 8(6): 89.

5. Muswede T (2018) South African press, land reform and public opinion: implications of prejudiced editorials on the quality of land discourse. Journal of Public Administration 53(2-1): 602-614.

6. Chigbu UE, Alemayehu Z, Dachaga W (2019) Uncovering land tenure insecurities: tips for tenure responsive land-use planning in Ethiopia. Development in Practice 29(3): 371-383.

7. Chigbu UE, Masum F, de Vries WT, Siegert F, Mekuria ZA, et al. (2016) Participatory rapid co-design for transformative resource governance research in the Gulf of Guinea. Current Opinion in Environmental Sustainability 20: 15-20.

8. Chigbu UE, Ntiador AM (2014) Ebola in West Africa: Implications on "Community Interaction" in Urban Nigeria. International Journal of Education and Research 2: 329-346.

9. Yates T, Vujcic JA, Joseph ML, Gallandat K, Lantagne D (2018) Water, sanitation, and hygiene interventions in outbreak response: a synthesis of evidence. Waterlines 37: 1-30

10. Bennett SD, Lowther SA, Chingoli F, Chilima B, Kabuluzi S, et al. (2018) Assessment of water, sanitation and hygiene interventions in response to an outbreak of typhoid fever in Neno District, Malawi. PloS one 13(2): e0193348.

11. Cohn SK (2008) Epidemiology of the Black Death and Successive Waves of Plague. Medical History 27: 74-100.

12. Bramanti B, Dean KR, Walløe L, Stenseth NC (2019) The third plague pandemic in Europe. Proceedings of the Royal Society 286(1901): 1-8.

13. Deen J, Mengel MA, Clemens JD (2020) Epidemiology of cholera. Vaccine 38(Suppl): A31-A40.

14. Miller GV (2016) Using information technology to model handwashing behavior and to improve policies impacting elementary school absenteeism due to influenza. Purdue University e-Pubs - Open Access Dissertation 681.

15. Tarro G (2017) Origin of the HIV and Evolutionary History of the Viruses. EC Microbiology 7: 87-91.

16. Grover A, Singh RB (2020) Urban Health and Wellbeing Indian Case Studies. Springer: India.

17. Chigbu UE (2019) Anatomy of women's landlessness in the patrilineal customary land tenure systems of sub-Saharan Africa and a policy pathway. Land Use Policy 86: 126-135.

18. Chae BK (2015) Insights from hashtag \#supplychain and Twitter Analytics: Considering Twitter and Twitter data for supply chain practice and research. International Journal of Production Economics 165: 247-259.

19.Zimmer M, Proferes N (2014) A topology of Twitter research: disciplines, methods, and ethics. Aslib Journal of Information Management 66(3): 250-261.

20. Chigbu UE (2019) Masculinity, men and patriarchal issues aside: How do women's actions impede women's access to land? Matters arising from a peri-rural community in Nigeria. Land Use Policy 81: 39-48.

21. Eguiluz IF, Buccini G, Fiedler AH, Rovelo N, de Cosío TG, et al. (2020) Content analysis of media coverage of breastfeeding in Mexico. Maternal \& Child Nutrition 16(2): e12905.

22. Sankoh 0 (2017) Why population-based data are crucial to achieving the Sustainable Development Goals. International journal of epidemiology 46(1): 4-7.

23. James KS, Rajan SI, Goli S (2020) Demographic and Health Diversity in the Era of SDGs. Economic \& Political Weekly 55(6): 46-52.

24. Larson PD, Larson NM (2019) The Hunger of Nations: An Empirical Study of Inter-relationships among the Sustainable Development Goals (SDGs). Journal of Sustainable Development 12(6): 39-47. 
25. Saric J, Blaettler D, Bonfoh B, Hostettler S, Jimenez E, et al. (2019) Leveraging research partnerships to achieve the 2030 Agenda: Experiences from North-South cooperation. GAIA-Ecological Perspectives for Science and Society 28(2): 143-150.

26. Abdullah TO (2018) A Content Analysis of Donald Trump and Hillary Clinton's Campaign Speeches and Framing of the 2016 Presidential Election. MSc thesis, University of Louisiana: Lafayette, USA.

27. Johnston FH, Jacups SP, Vickery AJ, Bowman DMJS (2007) Ecohealth and Aboriginal testimony of the nexus between human health and place. EcoHealth 4: 489-499.

28. Global Land Tool Network (2020) World Bank's 2020 Land and Poverty Conference postponed until further notice. Global Land Tool Network Web News, March.

29. Murar K (2020) Natural Products Show Postponed. Orange County Business Journal.

30. Inge $S(2020)$ Government pledges $€ 20 \mathrm{~m}$ to fight deadly coronavirus. Research Professional News.

31. Luyi X, Shen T (2020) At Coronavirus Epicenter, Personal Hygiene Habits Could Be Better, Survey Finds. Caixin Global - Society \& Culture, February.

32. Times of India (2020) Coronavirus outbreak: FSSAI working to improve hygiene at fish and meat markets. Times of India, February.

33. Ghosh P (2020) Air Pollution over China Reducing due to Industrial Shut Down. Intl Bus Times.

34. Pinkstone J (2020) EU Satellite image shows 30 PER CENT decrease in air pollution over China as coronavirus outbreak forces factories to close and citizens to go into quarantine. Daily Mail.

35. World Air Quality Index project (2020) Wuhan Air Pollution: Real-time Air Quality Index (AQI). 34. World Air Quality Index project 2020.

36. Antonio D, Mabikke S, Selebalo C, Chigbu UE, Espinoza J (2016) Securing Tenure through Responsive Land Use Planning: An Innovative Tool for Country Level Interventions. FIG Working Week, May 2-6, Christchurch, New Zealand.
37. Fomete T, Acworth J, Afana A, Kankeu RS, Bonnemaijer J, et al. (2018) Reframing local land use planning methods and tools in South-West Cameroon as a foundation for secure tenure, sustainable and equitable rural development, and REDD+. World Bank Conference on Land and Poverty, March 19-23, Washington DC.

38. Kim M, Gwak I, Koh J (2019) The strategies of advanced local spatial data infrastructure for Seoul Metropolitan Government. International Journal of Urban Sciences 23: 352-368.

39. Jiang Y, Wang H, Chen Y, He J, Chen L, et al. (2020) Clinical Data on Hospital Environmental Hygiene Monitoring and Medical Staff Protection during the Coronavirus Disease 2019 Outbreak. medRxiv.

40. British Broadcasting Service (2020) Coronavirus: Nasa images show China pollution clear amid slowdown.

41. Han L, Zhou W, Li W, Li L (2014) Impact of urbanization level on urban air quality: A case of fine particles (PM2. 5) in Chinese cities. Environmental Pollution 194: 163-170.

42. Pope III CA, Burnett RT, Thun MJ, Calle EE, Krewski D, et al. (2002) Lung cancer, cardiopulmonary mortality, and long-term exposure to fine particulate air pollution. Jama 287(9): 1132-1141.

43. Bridger JC, Alter TR (2008) An interactional approach to place-based development. Community Development. Journal of the Community Development Society 39(1): 99-111.

44. World Health Orgnisation (2020) COVID-19 Strategic Preparedness and Response Plan: Operational Planning Guidelines to Support Country Preparedness and Response. WHO, Switzerland.

45. Wilder-Smith A, Chiew CJ, Lee VJ (2020) Can we contain the COVID-19 outbreak with the same measures as for SARS? The Lancet Infectious Diseases 20(5): E102-E107.

46. Mosbergen D (2020) Don't Let Coronavirus Distract from Fighting Climate Change, UN Chief Warns. Huffington Post, March.

47. Hockley T (2020) Prevention or contamination? Coronavirus's silver lining. Politeia.

\section{Your next submission with Juniper Publishers will reach you the below assets}

- Quality Editorial service

- Swift Peer Review

- Reprints availability

- E-prints Service

- Manuscript Podcast for convenient understanding

- Global attainment for your research

- Manuscript accessibility in different formats

( Pdf, E-pub, Full Text, Audio)

- Unceasing customer service

Track the below URL for one-step submission https://juniperpublishers.com/online-submission.php 